Methodology Retrospective review of clinical records of babies discharged between Jan 2014 and Dec 2015 were compared to babies discharged between Jan 2016 to Dec 2017.

Old protocol, weaning done in increments of $30 \mathrm{~min}, 1 \mathrm{hr}$, $2 \mathrm{hr}, 3 \mathrm{hr}$ twice daily off, $6 \mathrm{hr}, 8 \mathrm{hr}, 10 \mathrm{hr}$ off with an OOS at each step. New protocol, general health and nutritional status guide the daytime $\mathrm{O}_{2}$ weaning. Weaning done in increments of $30 \mathrm{~min}, 2 \mathrm{hr}$ twice daily off, $6 \mathrm{hr}$ and $12 \mathrm{hr}$ off in day time followed 2-3 weeks later by two OOS, one in oxygen and one in air.

Results 33 babies were discharged each year on LTOT. Groups were comparable in mean birth weight $(\mathrm{kg})$, gestational age and comorbidities (table 1). New protocol was associated with shorter duration of $\mathrm{O}_{2}$ therapy (P value 0.005$)$. There was saving of $£ 3215.54$ for cost of oxygen in 2016-17. The parent satisfaction and the Friends and Family test score were $100 \%$.

\begin{tabular}{llll} 
Abstract G559(P) Table 1 & & \\
\hline & $\begin{array}{l}2014-2015 \\
\text { Mean (95\% CI) }\end{array}$ & $\begin{array}{l}2016-2017 \\
\text { Mean }(95 \% \mathrm{Cl})\end{array}$ & $\begin{array}{l}\text { P } \\
\text { value }\end{array}$ \\
\hline Gender ratio (M: F) & $13: 18$ & $16: 13$ & 0.350 \\
Birth weight Kg & $906.2(812.0-1000.4)$ & $822.9(720.0-925.8)$ & 0.226 \\
Gestational age(weeks) & $26.7(25.8-27.7)$ & $25.9(25.0-26.7)$ & 0.141 \\
comorbidity- PDA & $77 \%$ & $93 \%$ & 0.089 \\
comorbidity NEC & $48 \%$ & $44 \%$ & 0.782 \\
duration of LTOT & $499.3(360.0-638.5)$ & $280.8(232.4-329.2)$ & 0.005 \\
(days) & & & \\
No. of oximetry studies (OSS) & $13.6(10.5-16.6)$ & $15.4(12.6-18.3)$ & 0.364 \\
No. of outreach visits & $15.5(13.4-17.6)$ & $16.3(14.3-18.3)$ & 0.593 \\
No. of clinic visits & $6.5(5.4-7.5)$ & $5.2(4.3-6.0)$ & 0.056 \\
O2 cylinder cost per one patient & $291.59(230.24-$ & $200.82(176.40-$ & 0.008 \\
$\mathrm{f}$ & $352.94)$ & $225.24)$ & \\
\hline
\end{tabular}

Conclusions Structured monitoring and weaning based on clinical parameters and parental input led to shorter duration of LTOT The service users' feedback was $100 \%$ positive. Not all activities to provide this service were coded.

\section{G560(P) SAFETY OF THE KAISER PERMANENTE EARLY ONSET NEONATAL SEPSIS RISK CALCULATOR: A MULTI CENTRE RETROSPECTIVE STUDY}

${ }^{1} \mathrm{KJ}$ Pettinger, ${ }^{2} \mathrm{C}$ Breidenbach-Roe, ${ }^{2} \mathrm{KJ}$ Mayers, ${ }^{3} \mathrm{~T}$ Pettinger, ${ }^{4} \mathrm{~B}$ Phillips, ${ }^{2} \mathrm{~L}$ McKechnie. ${ }^{1}$ Neonatal unit, Bradford Teaching Hospitals NHS Foundation Trust, Bradford, UK; ${ }^{2}$ Neonatal unit, Leeds Teaching Hospitals Trust, Leeds, UK; ${ }^{3}$ Department of Obstetrics and Gynaecology, Leeds Teaching Hospitals Trust, Leeds, UK; ${ }^{4}$ Centre for Reviews and Dissemination, University of York, York, UK

\subsection{6/archdischild-2020-rcpch.478}

Aims Early onset neonatal sepsis (EOS) is a rare but significant cause of mortality and morbidity. Babies are treated based on risk factors and clinical indicators, according to National Institute for Health and Care Excellence (NICE) guidelines.

An electronic risk calculator has been developed by Kaiser Permanente, providing an estimation of EOS risk for babies $\geq 34$ weeks gestation. Blood cultures are recommended if the risk is $\geq 1 / 1000$ live births, plus empirical antibiotics if $\geq 3$ / 1000. The baby can be categorised as Well/Equivocal/Ill and a 'risk after clinical exam' score given.

We evaluated a large number of EOS cases to determine if it would be safe to introduce the calculator locally.

Methods A list of positive blood cultures from babies $\geq 34$ weeks gestation was obtained from two tertiary neonatal units. Study periods were December 2016-November 2017 and July 2016-July 2018 in the first and second trusts respectively.

The necessary data for the calculator was obtained from maternal and infant records, and the calculator score recorded. For babies treated based on 'risk factors' as per NICE, the score at birth was used. For babies treated according to clinical features, the score after examination was used.

The primary outcome was whether the calculator would have recommended empirical treatment in babies who went on to have EOS.

Following consultation with the research and development department, there was no requirement for ethical approval.

Results There were 21,242 births in the study period and 24 cases of culture-proven EOS. 3 babies were commenced on antibiotics outside of NICE guidance. 11 babies were commenced on antibiotics due to risk factors for EOS; 13 due to clinical indicators.

Of the 24 babies with culture-proven EOS, empirical antibiotics were only recommended by the calculator in seven.

Of the 11 babies commenced on antibiotics due to risk factors, 10 would have had delayed or missed treatment if the calculator had been used.

Conclusion Whilst the calculator has resulted in a substantial reduction in antibiotic use in published studies, we have demonstrated that a large proportion of EOS cases may be missed by the calculator. Currently, the benefit of introducing the calculator does not outweigh the risks.

\section{G561(P) SENSITIVITY OF THE KAISER PERMANENTE EARLY- ONSET SEPSIS CALCULATOR: A SYSTEMATIC REVIEW AND META-ANALYSIS}

${ }^{1} \mathrm{KJ}$ Pettinger, ${ }^{2} \mathrm{KJ}$ Mayers, ${ }^{2} \mathrm{~L}$ McKechnie, ${ }^{3} \mathrm{~B}$ Phillips. ${ }^{1}$ Neonatal Unit, Bradford Royal Infirmary, Bradford, UKi ${ }^{2}$ Neonatal Unit, Leeds Teaching Hospitals Trust, Bradford, UK; ${ }^{3}$ Centre for Reviews and Dissemination, University of York, Heslington, UK

\subsection{6/archdischild-2020-rcpch.479}

Aims Determining which babies should receive antibiotics for possible early onset sepsis (EOS) is challenging. Kaiser Permanente have developed an electronic calculator providing an individualised estimation of EOS risk.

We performed a meta-analysis quantifying how many culture positive EOS cases might be 'missed' using the calculator, in addition to cases missed using National Institute for Health and Care Excellence (NICE) guidelines (CG149 2012).

Methods A systematic literature search using a modified cluster technique, snowballing from studies citing the article in which the calculator was widely publicised (Kuzniewicz 2017) on Ovid MEDLINE, Embase, Maternity \& Infant Care Database and Google scholar. Reference lists were reviewed.

Studies were eligible if they presented data evaluating the calculator, either by retrospective case review or prospective cohort study and identified at least one episode of EOS. 